\title{
Names Crowned with Immortality
}

DOI: $10.1134 / \mathrm{S} 1061934811120148$

Some methods of analysis, analytical reagents, chemical reactions used in analysis, devices and even whole instruments bear names of their creators. These names are so numerous that an entire dictionary can be compiled. Without attempting this, let me limit myself to certain examples.

Beilstein test - a method for detecting halogens in organic substances, proposed by St. Petersburg organic chemist, Academician F.F. Beilstein (18381906).

Beckman spectrophotometer-one of the first, most probably the first, commercial spectrophotometer for the visible and near ultraviolet spectral region, designed by the American chemist and instrument maker A. Beckman in the late 1930s-early 1940s. Beckman is the founder of the famous instrumentmaking corporation; he lived 104 years (1900-2004).

Beer law-the law of light absorption proposed by Frenchman P. Buger (1698-1758) and German I.G. Lambert (1728-1777); the law goes under the name of German doctor August Beer (1825-1863), who published a resumptive work on optics, in which he described the above law. Now the law is usually called the Buger-Lambert-Beer law of light absorption.

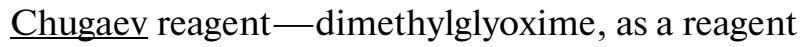
for nickel ions. It was described by L.A. Chugaev (1873-1922) in 1905.

Clark electrode-an electrode that allows the determination of oxygen by an electrochemical method; proposed in 1953 by American chemist L.K. Clark (1884-1964).

The Dumas method - a method for determining nitrogen in organic substances, developed in the first half of the 19th century by the French chemist J.B. Dumas (1800-1884).

Fehling's solution (liquid) - a reagent for detecting glucose; it was proposed by German chemist G.H. Fehling (1812-1885).

Fisher reagent-a multicomponent mixture containing, in particular, iodine and pyridine (or other bases) for determining water in organic solvents and other objects; it was proposed in the 20th century by K. Fisher.

Folgard method-one of the known methods of titrimetric analysis; it was developed by German chemist J. Folgard (1834-1910).
Griess-Iloshvay reagent-a mixture of $\alpha$-naphthylamine with sulfanilic acid, which gives red coloration with nitrite ions; it was proposed by German chemist I.P.Griess (1829-1888) and improved by Hungarian chemist L. Iloshvay (1851-1936).

Gooch crucible - a filtering glass crucible that can be multiply used in gravimetric analysis; it was proposed in 1878 by the American analytical chemist F. Gooch (1852-1929).

Ilkovic equation-one of the basic equations of polarographic analysis derived in the 1930 s by D. Ilkovic, a pupil of the founder of polarography, J. Heyrovsky (1890-1967).

Kjeldahl method-method for determining nitrogen in organic compounds widely used nowadays; it was proposed in 1883 by the Danish analytical chemist I.G. Kjeldahl (1849-1900).

L'vov platform - the key device for the electrothermal atomic absorption spectrometry, invented by B.V. L'vov (born 1932) in 1959.

Mamyrin mass reflectron-a device for ion reflection in an electrostatic mirror for time-of-flight mass spectrometry. It was designed in 1969 by B.A. Mamyrin (1919-2007) at the Leningrad Physicotechnical Institute.

Marsh test-a chemical method for determining arsenic; it was proposed in 1836 by the English chemist J.A. Marsh (1794-1846).

Mohr method - a titrimetric method based on the use of double ammonium and iron(II) sulfate (Mohr salt) as a titrant; it was proposed by German chemist K.F. Mohr (1806-1879) in 1852. The Mohr pipette and clamp are also known.

Nessler reagent-a reagent for determining ammonia; it was proposed by German agrochemist J. Nessler (1827-1905).

Nikolsky equation - the equation describing the work of ion-selective electrodes; it was proposed in the mid-1930s by B.P. Nikolsky (1900-1990), who went on to become an academician.

Sventitskii arc - an arc for atomic emission spectrochemical analysis supplied with alternate current via a so-called activated generator; it was proposed in 1941 by N.S. Sventitskii while working in the State Optical Institute (Leningrad).

Yu. A. Zolotov 